\title{
FORMULATION AND CHARACTERIZATION OF QUERCITRIN NANOEMULSION ISOLATED FROM Dendropthoe falcata AND ITS ANTIOXIDANT ACTIVITY TEST
}

\author{
S.Atun ${ }^{1, *}$, R. Arianingrum ${ }^{1}$, L. Cahyaningsih ${ }^{1}$, F. A. Pratiwi ${ }^{1}$, \\ R. Kusumaningrum ${ }^{1}$, and M. Khairuddean ${ }^{2}$ \\ ${ }^{1}$ Department of Chemistry Education, Faculty of Mathematic and Natural Science, Universitas \\ Negeri Yogyakarta, Jl. Colombo No. 1 Depok, Sleman, Yogyakarta, 55281 \\ ${ }^{2}$ School of Chemical Sciences, Universiti Sains Malaysia, 11800 Penang, Malaysia \\ E-mail: sriatun@uny.ac.id
}

\begin{abstract}
Quercitrin is the main component that can be isolated from the parasitic plant Dendrophthoe falcata and exhibits high antioxidant activity. The purpose of this study is to make a quercitrin nanoemulsion formulation and test its antioxidant activity. This research method uses spontaneous emulsion. Quercitrin is formulated by spontaneous emulsion with the addition of oil, tween 80 as a surfactant, and phosphate buffer $\mathrm{pH} 7.0$ as a water phase at low temperatures. Quercitrin nanoemulsion products are further characterized which include particle size, polydispersity index, zeta potential, physical properties, and stability. The antioxidant activity using the DPPH (2,2-diphenyl-1picrylhydrazyl) method. The results showed that quercitrin nanoemulsion had an average particle size diameter of 10.2 to $36.5 \mathrm{~nm}$, polydispersity index (PI) of less than 0.5 , and zeta potential of -1.8 to $-11.9 \mathrm{mV}$. Quercitrin nanoemulsion using virgine coconut oil (VCO) showed better stability than olive oil. The morphology of quercitrin nanoemulsion has the shape of a spherical particle. Quercitrin nanoemulsion is easily soluble in water and exhibits very high antioxidant activity like the original quercitrin.
\end{abstract}

Keywords: Antioxidant, Dendrophthoe falcata, Nanoemulsion, Quercitrin

(C) RASĀYAN. All rights reserved

\section{INTRODUCTION}

Dendrophthoe falcata is a parasitic plant of the Loranthaceae family, which is commonly found attached to the stems of Mangifera indica (Anacardiaceae), Melia azedarach (Meliaceae) and Psidium guajava (Myrtaceae) ${ }^{1}$. Loranthacea plants can be found in tropical and sub-tropical regions, but with a diversity of different species. D. falcata can be used as traditional medicine for the treatment of astringents, aphrodisiacs, narcotics, diuretics, pulmonary tuberculosis, asthma, and menstrual disorders ${ }^{2}$. Research on the leaves of $D$. falcata shows the presence of phenolic compounds with high antioxidant activity ${ }^{3}$. Quercitrin is a flavonoid glycoside that is a major compound in several species of Loranthus plants ${ }^{4}$ and also commonly found in plants, especially in the flowers of Zanthoxylum bungeanum ${ }^{5}$, and Anacardium occidentale $\mathrm{L}^{6}$. Quercetin shows high antioxidant activity ${ }^{4}$, antiviral against Murine coronavirus, dengue virus infection, and animal herpesvirus ${ }^{7,8}$, antiherpetic ${ }^{9}$, and anti-inflammatory ${ }^{10}$. Quercitrin is a phenolic compound that has four free phenol groups (Fig.-1), which plays an important role in the antioxidant activity. Quercitrin is insoluble in water, slightly soluble in acetone but soluble in ethanol or methanol. To be used as a medicinal or cosmetic ingredient, its effectiveness and solubility in water need to be increased thus, quercitrin is developed as nanoemulsion to be easily absorbed into the cell or the active sites.

In general, nanoemulsion can be defined as an oil-in-water emulsion with a very small droplet. The average particle size ranges from 20 to $200 \mathrm{~nm}$, making it look transparent or translucent ${ }^{11}$. Nanoemulsion is a system developed to deliver biologically active agents for controlled release and drug delivery in which it can increase the bio-availability of drugs that have low solubility in water. This is a promising

Rasayan J. Chem., 13(3), 1347-1356(2020)

http://dx.doi.org/10.31788/ RJC.2020.1335868

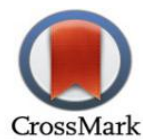


system for the fields of cosmetics, diagnostics, drug therapy and biotechnology ${ }^{12}$. Mechanisms for enhancing bio-availability include increased drug solubility, protection of drugs against hydrolysis enzymes, increased globular specific surface areas, and changes in permeability induced by surfactants ${ }^{13}$. The process of spontaneous nano-emulsification is influenced by the specific properties of oil, surfactant, and co-surfactant, the concentration and ratio of oil: surfactant: co-surfactant and the temperature where spontaneous nanoemulsions are formed. Therefore, only certain combinations of excipients can form spontaneous nanoemulsion systems. ${ }^{14}$ In this research, quercitrin will be developed in the form of nanoemulsion with the addition of virgin coconut oil (VCO), olive oil, tween 80 as a surfactant, and emulsified into a phosphate buffer $\mathrm{pH}$ of 7.0 at low temperature. The subsequent nanoemulsions were characterized by particle size, polydispersity index, zeta potential, physical properties, and stability. The synthesized nanoemulsion was then tested for its biological activity as an antioxidant using the DPPH (2,2-diphenyl-1-picrylhydrazyl) method.

\section{EXPERIMENTAL}

\section{Apparatus and Reagents}

The equipment used in this study are digital analytical scales, hotplate magnetic stirrer IKA C-MAG HS7, centrifuges, refrigerators, spectronic 20 (Genesys), scanning electron microscopy (SEM, Jeol T-300), TEM (Transmission Electron Microscopy) FEI Tecnai G2 20 S-Twin, particle size analyzer (PSA) Horiba SZ-100, spectrophotometer UV-2400PC series, spectrophotometer IR Shimadzu FTIR Prestige 21, spectrophotometer NMR Agilent 400. The reagent used included 2,2-diphenyl-1-picrylhydrazyl (DPPH, Aldrich), ascorbic acid (Sigma Aldrich, USA), quercitrin isolated from D. falcata hemiparasite on Melia azedarach, tween 80 or polyoxyethylene 20 sorbitan monooleate is a hydrophilic non-ionic surfactant used for synthesis (made in France CAS -No: 9005-65-6 Merck, Germany), phosphate buffer pH 7.0 (Merck), ascorbic acid (Sigma Aldrich, USA), aquadest, olive oil and virgin coconut oil (VCO) (bought from a supermarket in Yogyakarta, Indonesia).

\section{Preparation of Nanoemulsion Quercitrin}

The synthesis of nanoemulsion quercitrin was carried out by adding $0.01 \mathrm{~g}$ of quercitrin to a mixture of olive oil or VCO and tween 80 in different ratio of oil: tween $80(1: 4 ; 2: 4 ; 3: 4 ; 1: 5$; and 1:6) while stirring and heated at $70{ }^{\circ} \mathrm{C}$ for 20 minutes for the mixture to be homogeneous. Phosphate buffer $\mathrm{pH} 7.0$ was added dropwise for one hour at the heating temperature. The nanoemulsion quercitrin formed was then characterized by particle size, polydispersity index, zeta potential, physical properties such as solubility, $\mathrm{pH}$, viscosity, stability, and antioxidant activity (replicated 3 times).

\section{Determination of Particle Size, Polydispersity Index (PI), and Potential Zeta}

The particle size, polydispersity index, and zeta potential were measured using a dynamic light scattering particle size analyzer (Horiba SZ-100). About $10 \mathrm{~mL}$ of sample was placed into a cleaned cuvette and then inserted into the sample holder to be analyzed.

\section{Determination of Morphological Form of Nanoemulsion}

The morphological form of nanoemulsion was measure using TEM (Transmission Electron Microscopy) FEI Tecnai G2 20 S-Twin. At a voltage of 200kV TEM acceleration class with Angstrom sub-resolution $0.24 \mathrm{~nm}$ (point) and $0.188 \mathrm{~nm}$ (line), at a magnification of $25 \mathrm{x}-1025 \mathrm{kx}$ equipped with camera facilities and EDS (Energy Dispersive X-Ray Spectroscopy).

\section{Determination of Nanoemulsion Stability}

The physical stability test of nanoemulsion quercitrin was performed using centrifugation at a speed of $12,000 \mathrm{rpm}$ for 15 minutes. The samples were observed with parameters such as separation, deposition, creaming, and caking ${ }^{15}$. The stability test on the effect of storage at room temperature $\left(29-33{ }^{\circ} \mathrm{C}\right)$. The stability test was observed weekly for 5 weeks. Sample nanoemulsion quercitrin $(10 \mathrm{~mL})$ was placed into a test tube covered with aluminum foil and was left at room temperature for 5 weeks. Weekly observations on the parameter such as turbidity, creaming, and cracking was reported. 
RASĀYAN J. Chem.

Vol. 13 | No. 3 |1347-1356| July - September | 2020

\section{Determination of $\mathrm{pH}$ and Solubility in Water and Oil}

The $\mathrm{pH}$ measurement of the sample was done using a $\mathrm{pH}$ meter. Firstly, the electrodes were calibrated using a standard buffer of $\mathrm{pH} 4$ and $\mathrm{pH}$ 7. The calibration process was completed when the $\mathrm{pH}$ values are following the standard $\mathrm{pH}$. Then, the electrodes were dipped into each sample to obtain their $\mathrm{pH}$ value. The $\mathrm{pH}$ measurements were carried out at room temperature. Nanoemulsion type testing was done by the dissolution method by dissolving the sample into the water phase (ratio 1:100) and the oil phase (ratio $1: 100$ ). If the sample dissolves completely in the aquadest, the nanoemulsion type is classified as an oilin-water $(\mathrm{O} / \mathrm{W})$ nanoemulsion type whereas if the sample is fully soluble in the oil phase, the nanoemulsion type is classified as a water-in-oil nanoemulsion type $(\mathrm{W} / \mathrm{O})$.

\section{Determination of Viscosity}

The viscosity measurements were carried out using an Oswald viscometer. The sample was filled up in the Oswald tube to its limit and the flow velocity-time was observed. The test was done in triplicate and aquadest was used as a comparison. The density and viscosity of each sample were also measured with the relative comparison of aquadest. Based on the Poisseulle equation, the flow time of the sample fluid was compared to the liquid using the same tool.

\section{Determination of Antioxidant Activity}

DPPH (2,2-diphenyl-1-picrylhydrazyl) reagent is a free radical, which shows hydrogen acceptor ability towards antioxidants. Hence, it is commonly used in the DPPH assay for measuring the antioxidant activity. ${ }^{3,16}$ The sample was dissolved in ethanol (ratio 1:10). Five different concentrations were prepared from the dilution of each sample. A total of $5 \mathrm{~mL}$ of the dilution sample was mixed with $5 \mathrm{~mL}$ DPPH solution in ethanol $(0.12 \mathrm{mM})$ and the mixture was left at room temperature for 30 minutes. The sample was tested in triplicates and their absorption activities were measured using $\mathrm{UV}$ at a wavelength of 516 $\mathrm{nm}$. Vitamin $\mathrm{C}$ was used as a positive control and ethanol as a negative control. The inhibitory activity was calculated as the percentage of DPPH decreased compared to the control. Furthermore, the inhibitory activity calculation was used to calculate the antioxidant activity, expressed as $\mathrm{IC}_{50}$ (concentration of samples that have $50 \%$ inhibitory activity).

\section{RESULTS AND DISCUSSION}

Quercitrin used in this study was the main component isolated from the leaves of the D. falcata plant. Quercitrin is in the form of yellow solids and has a structure like in Fig.-1.

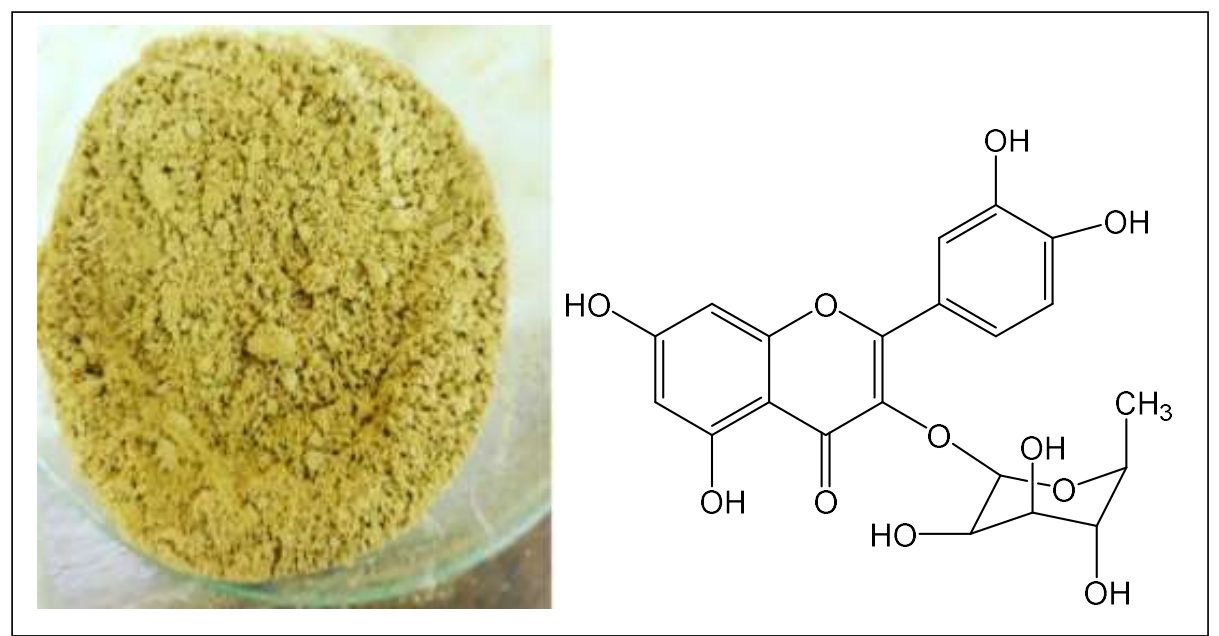

Fig.-1: Quercitrin (Quersetin-3-O-rhamnosida)

The structure of quercitrin based on the results of the analysis by spectroscopic method. UV spectroscopy data (in methanol solvents) showed wavelengths at $351.20 \mathrm{~nm}, 262.60 \mathrm{~nm}$, and $207.20 \mathrm{~nm}$. IR Spectrum (in $\mathrm{KBr})$ : $\mathrm{OH}(3233.65 \mathrm{~cm}-1)$, $\mathrm{C}-\mathrm{H}$ aliphatic $(2945.71 \mathrm{~cm}-1)$; $\mathrm{C}=\mathrm{O}(1651.88 \mathrm{~cm}-1)$, and $\mathrm{C}=\mathrm{C}$ aromatic 
RASĀYAN J. Chem.

Vol. 13 | No. 3 |1347-1356| July - September | 2020

$(1496.47$ and $1595.60 \mathrm{~cm}-1) .{ }^{13} \mathrm{C}$ NMR $\left(125 \mathrm{MHz}, \mathrm{CD}_{3} \mathrm{OD}\right): \mathrm{C}=\mathrm{O}(\delta \mathrm{C} 179.3), \mathrm{C}=\mathrm{C}(\delta 135.8$ and $158.0)$, two aromatic rings at $\delta(165.0,163.2,99.6,157.1,145.1,145.0,122.8,122.6,122.6,122.6116 .2$, $116.8,105.8$ and 99.6) ppm, six aliphatic carbon at $\delta 102.8-17.8 \mathrm{ppm}$ and the presence of methyl carbon at $\delta 17.8 \mathrm{ppm}$ confirm the existence of the rhamnoside sugar unit.

The ${ }^{1} \mathrm{H}$ NMR $\left(\mathrm{CD}_{3} \mathrm{OD}\right)$ : two proton at $\delta 6.22(1 \mathrm{H} ; \mathrm{d} ; \mathrm{J}=2.0 \mathrm{~Hz}$, aromatic proton $)$ and $\delta 6.43(1 \mathrm{H} ; \mathrm{d} ; \mathrm{J}=2.0$ $\mathrm{Hz}$, aromatic proton) ppm, signals proton at $\delta 7.36(1 \mathrm{H}, \mathrm{dd}, \mathrm{J}=8.0 ; 2.0) ; \delta 6.961 \mathrm{H}, \mathrm{d}, \mathrm{J}=8.0)$, and $\delta 7.46$ $(1 \mathrm{H}, \mathrm{d}, \mathrm{J}=2.0) \mathrm{ppm}$. Proton signals in the aliphatic region indicated the presence of a rhamnoside group, $\delta$ $5.47(1 \mathrm{H}, \mathrm{d}, \mathrm{J}=1.5 \mathrm{~Hz}) ; 4.18(1 \mathrm{H}, \mathrm{d}, \mathrm{J}=1.5) ; 3.31(1 \mathrm{H}, \mathrm{m}) ; 3.20(1 \mathrm{H}, \mathrm{m}) ; 3.0(1 \mathrm{H}, \mathrm{m})$; and $0.98(3 \mathrm{H}, \mathrm{d}$, $\mathrm{J}=2.0) \mathrm{ppm}$. The ${ }^{1} \mathrm{H}$ and ${ }^{13} \mathrm{C}$ NMR spectrum of quercitrin are shown in Fig.-2 and 3.The spectroscopic data are following the data reported from several references showed similarity to be concluded that the isolated compound is quercitrin ${ }^{17}$.

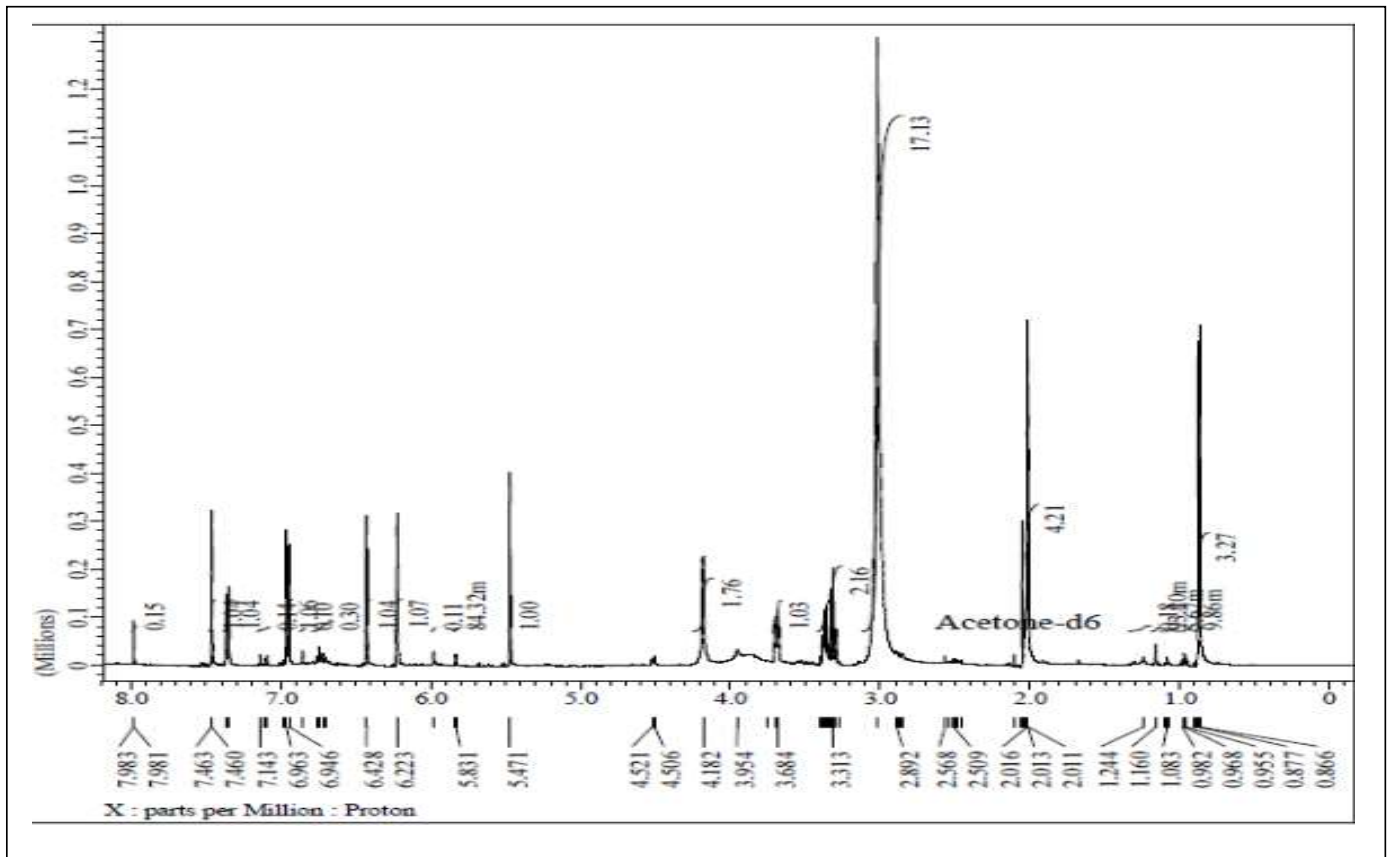

Fig-2: ${ }^{1} \mathrm{H}$ NMR Spectrum of Quercitrin in Aceton- $\mathrm{d}_{6}$

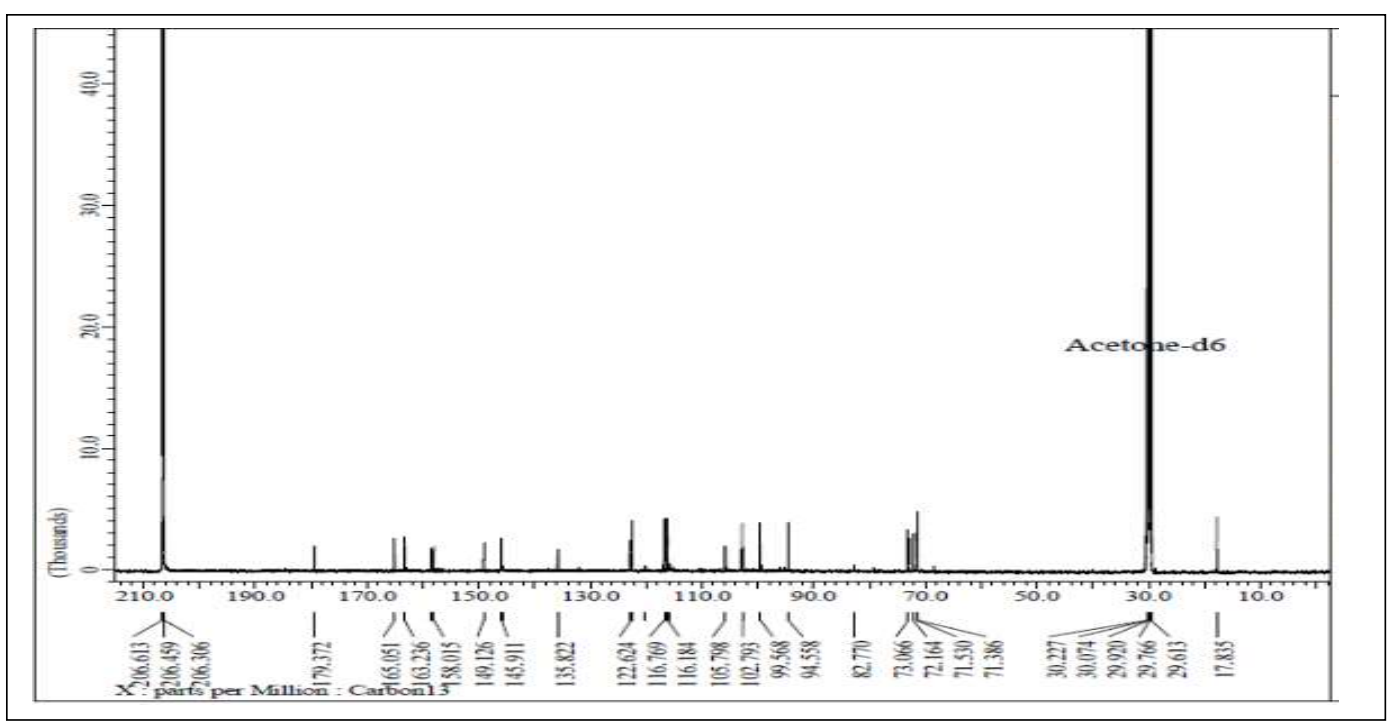

Fig.-3: ${ }^{13} \mathrm{C}$ NMR of Quercitrin in Aceton- $\mathrm{d}_{6}$ 
RASĀYAN J. Chem.

Vol. 13 | No. 3 |1347-1356| July - September | 2020

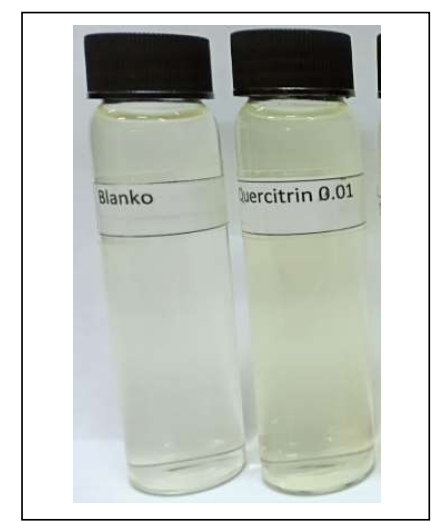

Fig.-4: Nanoemusion Quercitrin (B) and Control F (A)

The synthesis of quercitrin nanoemulsion was performed by dissolving quercitrin in a mixture of oil and tween 80. Different compositions of oil and tween 80 were used to obtain optimal results. Phosphate buffer was added slowly into the mixture to form an emulsion. The nanoemulsion type test which was carried out by dissolving nanoemulsion samples into water (1:100) indicated that the sample dissolved completely. Whereas the dilution test with oil (1:100) showed that the sample was not dissolved. Thus, the type of nanoemulsion quercitrin is oil in water $(\mathrm{O} / \mathrm{W})$. As shown in Fig.-4, nanoemulsion quercitrin was clear yellow compared to the control sample (without quercitrin) which showed a very small transparent droplet.

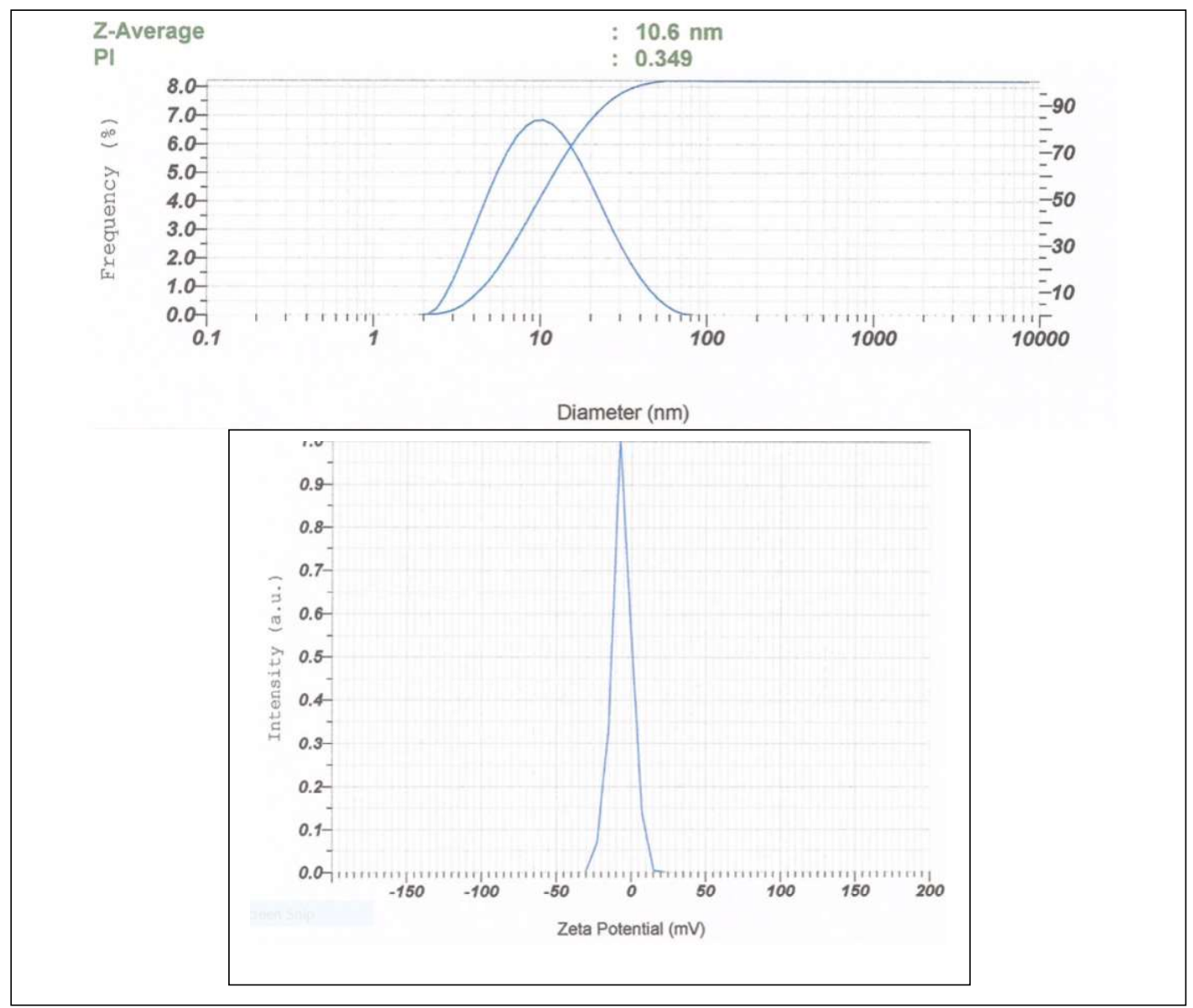

Fig.-5: The Graphic of Particle Size Analysis (PSA), Polydispersity Index (PI), and Zeta Potential Quercitrin Nanoemulsion of V-5

1351 
RASĀYAN J. Chem.

The particle size, polydispersity index (PI), and zeta potential of nanoemulsion quercitrin were analyzed using Horiba SZ-100. Figure-5 shows the graphical data of sample nanoemulsion quercitrin (DV-5). The graph shows that DV-5 has a particle size in the range of $2.1-72.8 \mathrm{~nm}$, with an average particle size of $10.8 \mathrm{~nm}$, polydispersity index (PI) of 0.349 , and zeta potential of $-6.1 \mathrm{mV}$. Table- 1 shows the data of particle size, polydispersity index (PI), and zeta potential of each quercitrin nanoemulsion. The characteristics of nanoemulsion were found to be strongly influenced by the properties of oil, surfactants and co-surfactants, as well as the concentration of the ingredients used. ${ }^{14}$

Table-1: The Data of Particle Size Analysis, Polydispersity Index (PI), and Zeta Potential of each Nanoemulsion Quercitrin

\begin{tabular}{c|c|c|c|c|c|c|c|c|c}
\hline No & Code & $\begin{array}{c}\text { Quercitrin } \\
(\mathrm{g})\end{array}$ & $\begin{array}{c}\text { VCO } \\
(\mathrm{mL})\end{array}$ & $\begin{array}{c}\text { Olive } \\
\text { oil } \\
(\mathrm{mL})\end{array}$ & $\begin{array}{c}\text { Tween } \\
80 \\
(\mathrm{~mL})\end{array}$ & $\begin{array}{c}\text { Phosphate } \\
\text { buffer } \mathrm{pH} \\
7.0(\mathrm{~mL})\end{array}$ & $\begin{array}{c}\text { Z- } \\
\text { average } \\
(\mathrm{nm})\end{array}$ & $\begin{array}{c}\text { PI } \\
\text { potensial } \\
(\mathrm{mV})\end{array}$ \\
\hline 1 & Control-E & - & - & 1 & 4 & 45 & 10.2 & 0.133 & -2.5 \\
\hline 2 & Control-F & - & 1 & 4 & - & 45 & 10.2 & 0.106 & -1.8 \\
\hline 3 & CZ-1 & 0.01 & - & 1 & 4 & 45 & 10.2 & 0.176 & -5.4 \\
\hline 4 & CZ-2 & 0.01 & - & 2 & 4 & 44 & 12.1 & 0.221 & -6.4 \\
\hline 5 & CZ-3 & 0.01 & - & 3 & 4 & 43 & 12.2 & 0.347 & -9.1 \\
\hline 6 & CZ-4 & 0.01 & - & 1 & 5 & 44 & 14.8 & 0.406 & -11.9 \\
\hline 7 & CZ-5 & 0.01 & - & 1 & 6 & 43 & 12.2 & 0.378 & -5.7 \\
\hline 8 & DV-1 & 0.01 & 1 & - & 4 & 45 & 10.7 & 0.100 & -3.8 \\
\hline 9 & DV-2 & 0.01 & 2 & - & 4 & 44 & 10.5 & 0.132 & -4.7 \\
\hline 10 & DV-3 & 0.01 & 3 & - & 4 & 43 & 36.5 & 0.373 & -4.8 \\
\hline 11 & DV-4 & 0.01 & 1 & - & 5 & 44 & 10.4 & 0.343 & -2.5 \\
\hline 12 & DV-5 & 0.01 & 1 & - & 6 & 43 & 10.6 & 0.349 & -6.1 \\
\hline
\end{tabular}

Note: The data were analyzed with SPSS 13.0 statistic software was used for analysis. Differences were considered significant at $\mathrm{p}<0.05$.

The synthesis of quercitrin nanoemulsion by spontaneous emulsification using VCO and olive oil, as well as the addition of different ratio of oil and tween 80 as surfactant showed an average particle size of less than $100 \mathrm{~nm}$, polydispersity index between 0.1 to 0.4 , and zeta potential of -1.8 to $11.9 \mathrm{mV}$. This showed that quercitrin nanoemulsion has a very small and uniform size. The addition of different ratios of oil and tween 80 surfactants showed different characteristics of the quercitrin nanoemulsion produced. Table 1 shows that there are significant differences in particle size at Z-average $(\mathrm{nm}), \mathrm{PI}$, and zeta potential $(\mathrm{mV})$ ( $p \leq 0.05$ ). However, all formulas in this study showed that the particle sizes are $<100 \mathrm{~nm}$. The use of tween 80 at a concentration of $20-40 \%$ of formula weight formed $\mathrm{O} / \mathrm{W}$ nanoemulsion with a particle size of $<100 \mathrm{~nm}^{15}$. Surfactants have an important role in the formation of nanoemulsions by lowering the interface tension between the oil and water phases. The influence of the addition of surfactants has a limit called CMC (Critical Micelle Concentration) in which at this limit, the interface tension is not reduced anymore with the addition of surfactants. ${ }^{18}$

Nanoemulsion has a particle diameter size of $<200 \mathrm{~nm}$ with a polydispersity index value of $0.2<\mathrm{PI}<0.6$ that is stable from the possibility of particle collision and gravity separation ${ }^{19}$. Zeta potential was used to predict dispersion stability and its value depends on the physicochemical properties of the drug, polymers, the electrolytes, and their adsorption. Nanoemulsion which has the potential zeta values above $+30 \mathrm{mV}$ or below $-30 \mathrm{mV}$ shows a stable colloidal system so that large particle loads can prevent particle aggregation based on electrostatic repulsion forces ${ }^{20}$. Thus, variations in the types of oil and the addition of tween 80 did not affect the nanoemulsion quercitrin obtained.

The results of quercitrin nanoemulsion characterization including $\mathrm{pH}$, viscosity, stability at centrifugation, and stability at room temperature storage are shown in Table-2. Quercitrin nanoemulsion stability test was observed based on the physical tests by centrifugation and stability on storage for 5 weeks. Physical stability test by centrifugation showed that all the test samples were stable because there was no separation after centrifuging for 30 minutes at a speed of $15000 \mathrm{rpm}$. Quercitrin nanoemulsion has a particle size diameter of $<100 \mathrm{~nm}$, so it has the kinetic stability. 
RASĀYAN J. Chem.

Vol. 13 | No. 3 |1347-1356| July - September | 2020

Table-2: The Characterization including pH, Viscosity, Stability at Centrifugation and Stability at Room Temperature Storage Quercitrin Nanoemulsion

\begin{tabular}{|c|c|c|c|c|c|c|c|c|c|c|}
\hline \multirow[t]{2}{*}{ No } & \multirow[t]{2}{*}{ Code } & \multirow{2}{*}{$\begin{array}{l}\text { Viscos } \\
\text { ity } \\
\text { (cP) }\end{array}$} & \multirow[t]{2}{*}{$\begin{array}{c}\text { S-in } \\
\text { W }\end{array}$} & \multirow[t]{2}{*}{$\mathrm{pH}$} & \multirow{2}{*}{$\begin{array}{c}\text { Stabi- } \\
\text { lity on } \\
\text { Centrifugati } \\
\text { on } \\
\end{array}$} & \multicolumn{5}{|c|}{$\begin{array}{l}\text { Stability at room temperature storage (\% damage to } \\
\text { observations at week: }\end{array}$} \\
\hline & & & & & & 1 & 2 & 3 & 4 & 5 \\
\hline 1 & $\begin{array}{c}\text { Phosphate } \\
\text { buffer } \mathrm{pH} \\
7.0\end{array}$ & 1.003 & $\mathrm{D}$ & 7.0 & clear & Stabil & clear & clear & clear & clear \\
\hline 2 & Control E & 1.638 & $\mathrm{D}$ & 6.7 & clear & clear & clear & clear & clear & clear \\
\hline 3 & Control F & 1.526 & $\mathrm{D}$ & 6.7 & clear & clear & clear & clear & clear & clear \\
\hline 4 & Aquadest & 0.999 & $\mathrm{D}$ & 7.0 & clear & clear & clear & clear & clear & clear \\
\hline 5 & $\mathrm{CZ1}$ & 1.685 & $\mathrm{D}$ & 6.7 & clear & clear & clear & clear & $\begin{array}{c}\text { Frik } \\
(15.2 \%)\end{array}$ & turbid \\
\hline 6 & $\mathrm{CZ2}$ & 1.768 & $\mathrm{D}$ & 6.7 & clear & clear & clear & clear & $\begin{array}{c}\text { Frik } \\
(18.18 \%)\end{array}$ & turbid \\
\hline 7 & $\mathrm{CZ3}$ & 1.638 & $\mathrm{D}$ & 6.7 & clear & clear & $\begin{array}{l}\text { Frik } \\
(9.1)\end{array}$ & $\begin{array}{c}\text { Frik } \\
(9.09 \%)\end{array}$ & $\begin{array}{c}\text { Frik } \\
(9.09 \%)\end{array}$ & turbid \\
\hline 8 & $\mathrm{CZ4}$ & 1.789 & D & 6.7 & clear & clear & clear & $\begin{array}{c}\text { Frik } \\
(3.64 \%)\end{array}$ & $\begin{array}{c}\text { Frik } \\
(3.64 \%)\end{array}$ & turbid \\
\hline 9 & $\mathrm{CZ5}$ & 2.300 & $\mathrm{D}$ & 6.7 & clear & clear & clear & $\begin{array}{c}\text { Frik } \\
(1.82 \%)\end{array}$ & $\begin{array}{c}\text { Frik } \\
(9.09 \%)\end{array}$ & turbid \\
\hline 10 & DV1 & 1.534 & $\mathrm{D}$ & 6.8 & clear & clear & clear & clear & clear & clear \\
\hline 11 & DV2 & 1.645 & $\mathrm{D}$ & 6.8 & clear & clear & clear & clear & clear & clear \\
\hline 12 & DV3 & 1.273 & $\mathrm{D}$ & 6.8 & clear & clear & clear & clear & clear & clear \\
\hline 13 & DV4 & 2.300 & $\mathrm{D}$ & 6.7 & clear & clear & clear & clear & clear & clear \\
\hline 14 & DV5 & 2.300 & $\mathrm{D}$ & 6.7 & clear & clear & clear & clear & clear & clear \\
\hline
\end{tabular}

Nanoemulsion without preservatives was left at room temperature and was observed every week. The stability test carried out at room temperature $\left(29-30{ }^{\circ} \mathrm{C}\right)$ showed that quercitrin nanoemulsion using VCO was relatively more stable than olive oil. In week 2 , quercitrin nanoemulsion with olive oil began to form surface damage which was increased, in the following week. By the fifth week, all samples with olive oil appeared to be cloudy. However, samples with VCO still looked clear in the fifth week. This is influenced by the content of fatty acids in the oil. The dominant fatty acid content in VCO is saturated fatty acid (lauric acid), while the dominant fatty acid content in olive oil (70.71-75.59\%) is an unsaturated fatty acid (oleic, acid and linoleic acid) ${ }^{21}$. Unsaturated fatty acids are more easily oxidized at room temperature compared to the saturated fatty acids. Turbidity or sedimentation damaged the nanoemulsion in which the oil is no longer wrapped with surfactants. Tween 80 as a non-ionic surfactant is not easily influenced by acid and electrolyte conditions so it remains active as a surface layer between oil and water. In the nanoemulsion system which is stabilized by the ionic surfactants, the surface charge came from ions contained in the surfactant hydrophilic groups.

Quercitrin nanoemulsion has a $\mathrm{pH}$ of 6.7 and 6.8. The use of phosphate buffer $\mathrm{pH} 7.0$ as the water phase maintains the $\mathrm{pH}$ of the nanoemulsion produced, so quercitrin is relatively safe to be used as a medicinal ingredient. The viscosity of quercitrin nanoemulsion ranges from 1.6 to $2.3 \mathrm{cP}$ which is not much different from the viscosity of water. The viscosity of the preparation affects the release of active ingredients from the base to the membrane surface. The viscosity of nanoemulsion is low which causes the penetration speed of active substances to be faster and easier thereby increasing the mobility of the active ingredients. The smaller the particle size, the surface area of the substance increases, so that it will accelerate its solubility. The increased surface area allows greater interaction between the solute and the solvent. A size of less than $100 \mathrm{~nm}$ makes the nanoemulsion more soluble compared to emulsions. The viscosity of the solutes can also affect the solubility of a substance thus, the solute flows faster. Quercitrin nanoemulsion also has a polydispersity index smaller than 0.05 . A low polydispersity index value 
RASĀYAN J. Chem.

Vol. 13 | No. 3 |1347-1356| July - September | 2020

indicated that the dispersion system formed is more stable for a long period of time $\mathrm{e}^{22}$. Based on the results of morphological observations using TEM (Fig.-6) nanoemulsion quercitrin has the shape of spherical particles because it looks like a circle of liquid coated by a thick line. Thick lines are emulsifiers in the form of tween 80 that protect oil, while the circles contained in thick lines are quercitrin and oil.

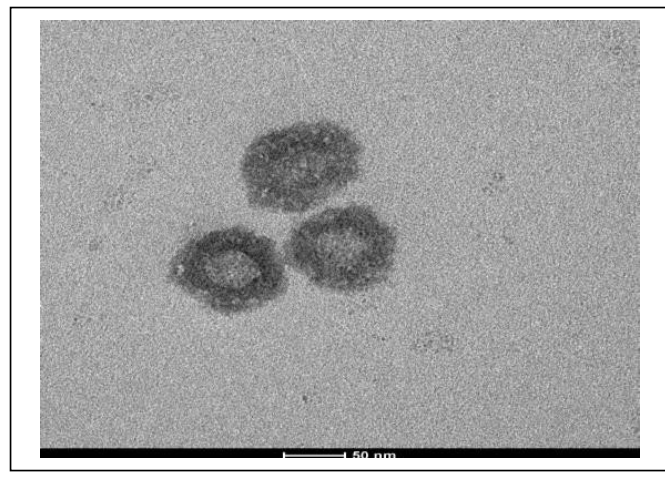

Fig.-6: The Morphological Form of Quercitrin Nanoemulsion by TEM

The antioxidant activity of quercitrin nanoemulsion was tested through the DPPH method and the results are presented in Table-3. The role of antioxidants is the interaction between the phenolic compounds and free radicals. The reaction of DPPH, a free radical, with the phenolic compounds were characterized by the color changes from dark purple to light purple or colorless. The color changes indicated the potential for radical capture of antioxidant compounds. Each sample was tested for its antioxidant activity using DPPH reagents at various concentrations. The relationship between concentration and percent inhibition activity was further expressed in a linear regression equation. The linear regression equation was used to calculate the $\mathrm{IC}_{50}$ value which stated the percent of inhibitory activity at a concentration of $50 \mu \mathrm{g} / \mathrm{mL}$. The antioxidant activity expressed as $\mathrm{IC}_{50}(<20 \mu \mathrm{g} / \mathrm{mL})$ in both quercitrin and quercitrin nanoemulsion showed high activity. Thus, changes in the form of quercitrin nanoemulsions still show high activity. The results of the antioxidant activity test of each quercitrin nanoemulsion product obtained in various variations of the composition showed no significant difference. Therefore the particle size of quercitrin nanoemulsion at various compositions obtained in this study was less than $100 \mathrm{~nm}$. The advantages of quercitrin nanoemulsion products are that they are soluble in water, making it easier to formulate when used as medicine or cosmetics. Nanoemulsion is widely known to increase the bioavailability of drugs that have low solubility in water. Also, it can protect the drug against hydrolysis enzymes, increases the surface area of particles, and changes in permeability caused by surfactants ${ }^{13}$. Research on Rhaphidophora pinnata ethanol extract with high levels of phenolic compounds in the form of nanoparticles has antimutagenic activity and protective effect against oxidative DNA damage ${ }^{23}$.

Table-3: Antioxidant Properties of Quercitrin Nanoemulsion

\begin{tabular}{c|c|c|c|c}
\hline No & Code & Z-average $(\mathrm{nm})$ & Regression Equation & $\mathrm{IC}_{50} \mu \mathrm{g} / \mathrm{mL}$ \\
\hline 1 & CZ-1 & 10.2 & $\begin{array}{c}\mathrm{y}=2.1888 \mathrm{x}+20.06 ; \\
\mathrm{r}^{2}=0.9612\end{array}$ & 13.67 \\
\hline 2 & $\mathrm{CZ}-2$ & 12.1 & $\begin{array}{c}\mathrm{y}=2.9839 \mathrm{x}+14.852 \\
\mathrm{r}^{2}=0 . .9928\end{array}$ & 11.78 \\
\hline 3 & $\mathrm{CZ}-3$ & 12.2 & $\begin{array}{c}\mathrm{y}=5.5426 \mathrm{x}+1.4687 \\
\mathrm{r}^{2}=0.9275\end{array}$ & 8.75 \\
\hline 4 & $\mathrm{CZ}-4$ & 14.8 & $\begin{array}{c}\mathrm{y}=3.2224 \mathrm{x}+2.4578 \\
\mathrm{r}^{2}=0.9195\end{array}$ & 14.75 \\
\hline 5 & $\mathrm{CZ}-5$ & 12.2 & $\begin{array}{c}\mathrm{y}=8.803 \mathrm{x}+17.21 \\
\mathrm{r}^{2}=0.934\end{array}$ & 4.82 \\
\hline 6 & $\mathrm{DV}-1$ & 10.7 & $\begin{array}{c}\mathrm{y}=3.3265 \mathrm{x}+1.5708 \\
\mathrm{r}^{2}=0.9971\end{array}$ & 14.55 \\
\hline 7 & $\mathrm{DV}-2$ & 10.5 & $\begin{array}{c}\mathrm{y}=5.657 \mathrm{x}+4.3539 \\
\mathrm{r}^{2}=0.9828\end{array}$ & 8.07 \\
\hline
\end{tabular}


RASĀYAN J. Chem.

Vol. 13 | No. 3 |1347-1356| July - September | 2020

\begin{tabular}{|c|c|c|c|c|}
\hline 8 & DV -3 & 36.5 & $\begin{array}{c}\mathrm{y}=11.249 \mathrm{x}+3.9322 \\
\mathrm{r}^{2}=0.9919\end{array}$ & 4.09 \\
\hline 9 & DV-4 & 10.4 & $\begin{array}{c}\mathrm{y}=6.2761 \mathrm{x}+0.7142 \\
\mathrm{R}^{2}=0.9504\end{array}$ & 7.85 \\
\hline 10 & DV-5 & 10.6 & $\begin{array}{c}\mathrm{y}=8.763 \mathrm{x}+23.315 \\
\mathrm{r}^{2}=0.9967\end{array}$ & 3.04 \\
\hline 11 & Quercitrin & - & $\begin{array}{c}\mathrm{y}=8,2225 \mathrm{x}+8,8838 \\
\mathrm{r}^{2}=0,981\end{array}$ & 5.00 \\
\hline 12 & $\begin{array}{l}\text { Ascorbic } \\
\text { acid }\end{array}$ & - & $\begin{array}{c}\mathrm{y}=13.76 \mathrm{x}+32.51 \\
\mathrm{r}^{2}=0.883\end{array}$ & 1.27 \\
\hline
\end{tabular}

\section{CONCLUSION}

Quercitrin nanoemulsion can be formulated using oil, tween 80 as a surfactant, and phosphate buffer $\mathrm{pH}$ 7.0 as an aqueous phase. Quercitrin nanoemulsion has an average particle size diameter of 10.2 to 36.5 $\mathrm{nm}$, polydispersity index (PI) less than 0.5 , and zeta potential of -1.8 to $11.9 \mathrm{mV}$. The morphology of quercitrin nanoemulsion has the shape of a spherical particle. Quercitrin nanoemulsion products exhibit good physical stability on the effects of centrifugation and storage. Quercitrin nanoemulsion with VCO (oil phase) is more stable than olive oil at room temperature for 5 weeks. Original quercitrin and quercitrin nanoemulsions showed very high antioxidant activity.

\section{ACKNOWLEDGMENT}

This research was funded by the Minister of Research and Technology of the Directorate of Higher Education, Indonesia for funding basic research grant, Number: 194/SP2H/LT/DRPM/2019, and foreign seminar aid program (BSLN, MENRISTEK DIKTI) Indonesia has provided financial assistance to attend the ISTEC 2019 international seminar. The author is very grateful for the research grant.

\section{REFERENCES}

1. S.Z. Moghadamtousi, M. Noor, A. Kamarudin, C.K. Chan, B.H. Goh, and H.A. Kadir, The American Journal of Chinese Medicine, 42, 23 (2014), DOI:10.1142/S0192415X14500025

2. K. Subhashini, P. K. Ratna Kumar and G. Gaddeyya, Tropical Plant Reasearch, 6, 514 (2019), DOI: 10.22271/tpr.2019.v6.i3.064

3. S. Atun S, Z.Q. A'yun, N. Lutfia, and S. Handayani, Journal of Physics: Conference Series, 1156, 1 (2019), DOI:10.1088/1742-6596/1397/1/012024

4. E. Sharquie, A. Adil, Noaimi, B. A. Saleh, Journal of Cosmetics, Dermatological Sciences and Applications, 6, 24(2016), DOI:10.4236/jcdsa.2016.61004.

5. Y.J. Zhang, D.M. Wang, L.N. Yang, D. Zhou, J.F. Zhang, PLoS ONE, 9, 1(2014), DOI: 10.1371/journal.pone.0105725

6. O.O. Ajileye, E.M. Obuotor, E.O. Akinkunmi, and M.A Aderogba, Jounal of King Saud University Science, 27, 244(2015), DOI:10.1016/j.jksus.2014.12.004

7. K.H. Chiow, M.C. Phoon, T. Putti, B.K.H. Tan, and V.T. Chow, Asian Pacific Journal Tropical Medicine, 9, 1(2016), DOI:10.1016/j.apjtm.2015.12.002.

8. R.M. Parreira, I.C. Simoni, O.A. Fávero, J.H.G. Lago, M.C. Mecchi, K.H. Barrosa, and M.J.B. Fernandes, Journal of Applied Pharmaceutical Science., 7, 122(2017), DOI: 10.7324/JAPS.2017.70719

9. R. Garrett, M.T.V. Romanos, R.M. Borges, M.G. Santos, L. Rocha, A.J.R. Silva, Brazilian Journal Pharmacognosy, 22, 306 (2012), DOI:10.1590/S01026-95X2012005000003

10. M. Comalada, D. Camuesco, S. Sierra, I. Ballester, J. Xaus, J. Gilvez, and A. Zarzuelo A, European Journal Immunology, 35, 584(2005), DOI:10.1002/eji.200425778

11. J.M. Gutierrez, C. Gonzalez, A. Maestro, I. Sole, C.M. Pey, and J. Nolla, Current Opinion in Colloid \& Interface Science, 13, 245(2008), DOI: 10.1016/j.cocis.2008.01.005

12. P. Shah, P.K. Shelat, D. Bhalodia, Systematic Reviews in Pharmacy, 1, 24(2010), DOI: $10.4103 / 0975-8453.59509$

13. S.V.R. Rao and J. Shao, International Journal of Pharmaceutics. 362, 1(2008), 
RASĀYAN J. Chem.

Vol. 13 | No. 3 |1347-1356| July - September | 2020

DOI: $10.1016 /$ j.ijpharm.2008.05.018

14. P. Izquierdo, J. Esquena, J. Feng, T. Tadros, Journal of Colloid and Interface Science 285, 388(2005), DOI:10.1016/j.jcis.2004.10.047

15. N. Salim, M. Basri, M.B.A. Rahman, D.K. Abdullah, H. Basri, and A.B. Salleh, Journal Nanomedicine Nanotechnology, 2, 1(2011), DOI: 10.4172/2157-7439.100011

16. M. Simorangkir, W. Hutabarat, B. Nainggolan and S. Silaban, Rasayan Journal of Chemistry, 12, 959 (2019), DOI: 10.31788/RJC.2019.1225095

17. R. Hardiyanti, L. Marpaung, I. K. Adnyana, and P. Simanjuntak, Rasayan Journal of Chemistry, 12, 1022 (2019), DOI: 10.31788/RJC.2019.1235353

18. L.L. Schramm, Surfactants: Fundamentals and Applications in the Petroleum Industry, Cambridge University Press, United Kingdom, pp. 9-10 (2000).

19. S. Z. Smrity, A.H.M Saifuddin, S. Sultana, American Journal of Biomedicine and Life Science, 4, 49 (2016), DOI: $10.11648 /$ j.ajbls.20160403.15

20. K. Gurpreet and S. K. Sing. Indian Journal Pharmacetical Science, 80, 781(2018), DOI: $10.4172 /$ pharmaceutical-sciences. 1000422

21. Ş. Irmak and Ö. Tokuşoğlu, S, Journal Nutrition Food Science, 7, 1(2017), DOI:10.4172/21559600.1000582

22. L. Gao, D. Zhang, and M. Chen Jornal of Nanoparticle Research, 10, 13(2008), DOI: $10.1007 / \mathrm{s} 11051-008-9357-4$.

23. Sumaiyah, Masfria and A. Dalimunthe, Rasayan Journal of Chemistry, 11, 505(2018), DOI:10.31788/RJC.2018.1122068

[RJC-5868/2020] 